\title{
Determinants of attitudes to carnivores: implications for mitigating human-carnivore conflict on South African farmland
}

\author{
Michelle Thorn, Matthen Green, Kelly Marnewick and Dawn M. Scott
}

\begin{abstract}
Human-wildlife conflict is increasingly prevalent, particularly in relation to carnivores in non-protected areas of Africa. Quantifying the attitudes of land owners towards carnivores and understanding the factors that influence these attitudes are instrumental in conservation planning and reducing persecution-related threats to carnivores. However, information about attitudes to carnivores in Africa, and South Africa in particular, is scarce. To obtain such data we interviewed 170 commercial game and livestock farmers in two ecologically important rural areas of northern South Africa. Responses to statements about carnivore management, stock protection and predation were generally positive. However, $62 \%$ of respondents believed carnivores to be financially damaging and $35 \%$ thought them overly abundant. Many respondents (41\%) were unwilling to tolerate even low levels of predation and considered persecution of carnivores to be the cheapest form of stock protection (31\%). Attitudes were significantly more positive among respondents who did not kill carnivores than among those who did. Generalized linear regression coupled with informationtheoretic analysis showed that attitudes to carnivores were determined by a combination of cultural and land-use attributes more than by economic factors such as stock holdings or predation losses. The results elucidate potential targets for mitigation activities and facilitate the development of communication, education and extension activities specifically designed to appeal to intended recipients and address prevalent motives for persecuting carnivores.
\end{abstract}

Keywords Human-wildlife conflict, perception, predation, questionnaire interview, South Africa

This paper contains supplementary material that can be found online at http://journals.cambridge.org

\footnotetext{
MiCHELLE THORN ${ }^{*} \dagger$ (Corresponding author) and DAWN M. SCOTT University of Brighton, Biology Division, Huxley Building, Lewes Road, Moulsecoomb, Brighton, BN2 4GJ, UK. E-mail Michelle.thorn@hotmail.com

Matthew Green Endangered Wildlife Trust, Carnivore Conservation Programme, Johannesburg, South Africa

Kelly Marnewick† Centre for Wildlife Management, Hatfield Experimental Farm, University of Pretoria, Pretoria, South Africa

${ }^{*}$ Also at: Centre for Wildlife Management, Hatfield Experimental Farm, University of Pretoria, Pretoria, South Africa

†Also at: Endangered Wildlife Trust, Carnivore Conservation Programme, Johannesburg, South Africa

Received 4 December 2012. Revision requested 11 February 2013.

Accepted 15 April 2013. First published online 8 May 2014.
}

\section{Introduction}

7 he current rate of the extinction of species is estimated 1 to be 1,000 times higher than in the fossil record (Pimm et al., 1995). The main causes of this biodiversity crisis are human population growth and range expansion, and increased consumption of natural resources (Baillie et al., 2010). Impacts on terrestrial mammals include widespread reduction in range, fragmentation and loss of habitat, loss of prey, population decline and local, regional and, in some cases, global extirpation of species (Baillie et al., 2010). Species of the order Carnivora are especially susceptible to these threats because their high trophic position restricts them to low-density populations that are inherently vulnerable to demographic and environmental stochasticity (Woodroffe \& Ginsberg, 2000). Greater proximity and reduced resource availability have intensified competition between people and carnivores, leading to increased human-carnivore conflict globally (Graham et al., 2005; Inskip \& Zimmermann, 2009). Twenty-seven percent of carnivore species are considered extinct or threatened with extinction in the wild (IUCN, 2012).

In Africa many carnivore populations reside outside protected areas (Mackinnon \& Mackinnon, 1986), where they can pose a threat to human lives (Graham et al., 2005). In agricultural areas carnivores may prey upon animals that have nutritional, financial or recreational value to people (Graham et al., 2005). People frequently kill carnivores in an effort to prevent attacks on humans or livestock (Graham et al., 2005; Inskip \& Zimmermann, 2009) and this has potentially severe implications for the conservation of threatened species. For example, a Namibian study attributed $47.6 \%$ of cheetah Acinonyx jubatus mortality to persecution by humans on farmland. Reducing indiscriminate persecution of carnivores in agricultural areas of Africa may therefore play an important role in conserving threatened species. Furthermore, indiscriminate persecution of meso-predators (e.g. black-backed jackals Canis mesomelas and caracals Caracal caracal) may trigger compensatory demographic responses such as increased natality and immigration (Prugh et al., 2009), potentially increasing rates of predation (Marker et al., 2003; Ogada et al., 2003; Thorn et al., 2012). Thus, in areas where meso-predators remain relatively abundant, lowering the rate of indiscriminate persecution may benefit both human and carnivore populations.

Reducing indiscriminate killing of carnivores requires a sound understanding of the factors motivating this 


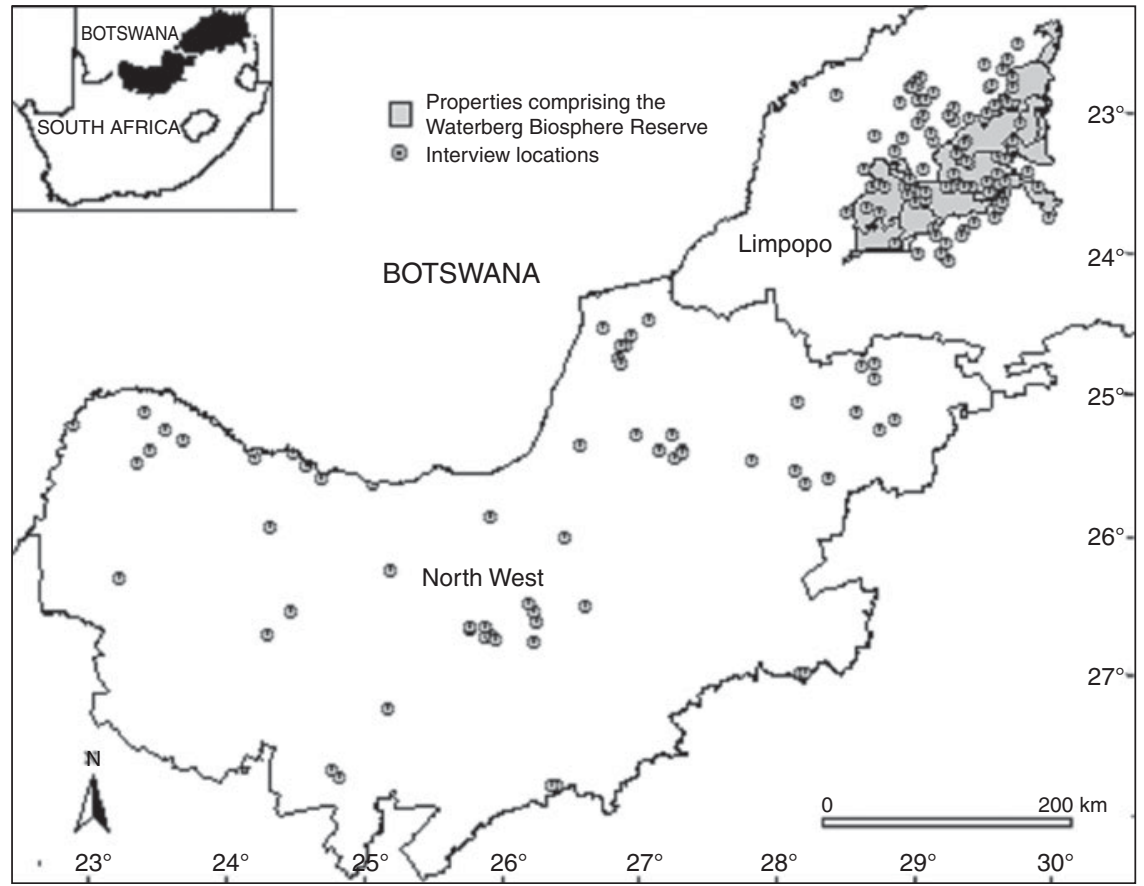

FIG. 1 Sites where interviews were carried out in the North West and Limpopo Provinces of South Africa. The shaded areas on the inset show the location of the provinces in South Africa. behaviour, which include social and psychological factors that affect the decision-making process (St John et al., 2010; White \& Ward, 2010). One such factor is attitude, defined here as a positive or negative response to carnivores. Attitudes affect community support for conservation and management initiatives (Naughton-Treves et al., 2003; Davenport et al., 2010) and influence individual behaviour towards carnivores (Marker et al., 2003; Lindsey et al., 2005b; Zimmermann et al., 2005). Thus, conservation and conflict-mitigation initiatives often seek to change damaging human behaviour by altering underlying attitudes (St John et al., 2010).

We focused on attitudes to carnivores at privately owned commercial game and livestock farms because those land uses cover the majority of agricultural land in our study areas (Tladi et al., 2002; de Klerk, 2003). People inhabiting these areas co-exist with medium and large-sized carnivore species, including brown hyaena Hyaena brunnea, leopard Panthera pardus, caracal, black-backed jackal, cheetah and African wild dog Lycaon pictus. Current levels of persecution threaten brown hyaenas, cheetahs and African wild dogs (Friedmann \& Daly, 2004; Thorn et al., 2012). Indiscriminate persecution of jackals and caracals appears to be a widespread social norm (Thorn et al., 2012). Previous studies have assessed local determinants of persecutory behaviour towards carnivores (Thorn et al., 2012) but not the perceptions and attitudes that motivate such behaviour. This is an important omission because attitudes and behavioural intentions are often uncorrelated with actual behaviour (Romanach et al., 2007; St John et al., 2010; Heberlein, 2012). If behaviour reflects attitudes to carnivores in our study area, investigating attitude determinants will inform the design and targeting of relevant conflictmitigation activities. If not, conflict-mitigation strategies seeking to reduce persecution by altering attitudes may be a waste of precious resources.

This study seeks to evaluate the effect of social, economic and land-use variables that may influence attitudes to carnivores in South Africa. Predictions regarding these determinants are that attitudes are more positive among game farmers than those with other land uses (Lindsey et al., 2005b), more positive among English-speaking farmers than among Afrikaans-speaking farmers (Lindsey et al., 2005b), and negatively related to age (Lindsey et al., 2005b; Zimmermann et al., 2005) and stock losses (Zimmermann et al., 2005). We would expect stock holdings and farm size to be positively related to attitude, reflecting the relative affluence of land owners and the concomitantly reduced impact of financial losses as a result of predation (Romanach et al., 2007). Our analysis seeks to test these predictions, evaluate which determinants exert the greatest influence on attitudes to carnivores and confirm whether attitudes are correlated with persecutory behaviour.

\section{Study area}

The study area comprised $116,320 \mathrm{~km}^{2}$ of commercial farmland in the North West Province of South Africa and the $11,090 \mathrm{~km}^{2}$ Waterberg area of the adjacent Limpopo Province, which includes the UNESCO Waterberg Biosphere Reserve and surrounding areas of the Waterberg District Municipality (Fig. 1). The Waterberg area has the highest proportion of grazing land in Limpopo (de Klerk, 2003) and $54 \%$ of the North West Province is used for grazing 
TABLE 1 The proportion of respondents who agreed or strongly agreed with each of the 10 attitude statements.

Attitude statement $\%$ agreement

1. This site cannot tolerate any carnivores.

7.6

2. Carnivores cost me money.

61.8

3. Carnivores are wasteful \& take far more than they need.

14.6

4. I would like to know more about non-lethal anti-predation methods.

80.5

5. Carnivores should only live inside fenced areas from which they cannot escape. 9.4

6. It does not matter if carnivores kill a few of my animals.

58.8

7. If you remove/kill a carnivore it is simply replaced by another one.

82.3

8. There is nothing good about carnivores.

5.5

9. I would like to have fewer carnivores in this area.

35.4

10. It is cheaper to kill carnivores than it is to protect my stock by other means.

30.5

(Tladi et al., 2002). Farming of cattle and small-stock (pigs Sus scrofa, sheep Ovis aries and goats Capra aegagrus hircus) is common (Department of Agriculture, Forestry and Fisheries, 2010). Many commercial farmers combine game and livestock farming (henceforth, mixed farmers).

\section{Methods}

\section{Interview methods and questionnaire design}

We surveyed commercial game and livestock farms throughout the North West Province between October 2006 and September 2008, and in the Waterberg area of the adjacent Limpopo Province during March-August 2011. Respondents were recruited initially by opportunistically approaching as many attendees as possible at local farming forums, and further contacts were supplied by each participant. Interviews were administered in person and in private (usually at the respondent's home) by MT and MG. Each lasted c. 40 minutes and was based on a semistructured questionnaire (Supplementary Material 1). The questionnaire was piloted prior to use to ensure clarity, resulting in minor amendments. It contained four sections, based on (1) characteristics of respondents and their farms, (2) carnivore species present and predator-prey interactions, (3) use of anti-predation measures, including lethal control of carnivores, and (4) attitudes towards carnivores. All respondents were assured of anonymity and confidentiality.

Attitudes to carnivores were explored using 10 statements (Table 1), chosen following a literature review and preliminary discussions with local researchers, conservation workers and land owners. This process also informed the selection of the predictor variables used in generalized linear models. Responses to each statement were measured on a five-point Likert scale (strongly agree, agree, unsure, disagree, strongly disagree).

Cultural group was inferred from the respondent's first language. Respondents estimated game and livestock abundance as well as the number of animals killed by carnivores. The accuracy of abundance and predation estimates for extensively managed animals (usually plains game but sometimes cattle) may vary because those animals can be difficult to detect and are counted infrequently (usually annually or bi-annually). However, despite potential bias, such data were not available from any other source. Many respondents cited lack of population growth in game species as indirect evidence of predation but such losses were not recorded because they were unquantifiable and could have been caused by factors other than carnivore predation.

\section{Analysis}

We coded responses to the attitude statements on a scale of one (strongly negative) to five (strongly positive), the sum of which gave a total attitude score per respondent. The reliability of the total scores was tested using Cronbach's $\alpha$. Questions that were not internally consistent were removed, ensuring that the total of the remaining questions (henceforth, the composite attitude score) was truly additive and reflected overall attitude towards carnivores (Cortina, 1993).

We then evaluated the effect of possible determinants, using a generalized linear regression model with a Poisson error distribution and a log link function. We first created a Spearman's rank correlation coefficient matrix and excluded predictor variables that were inter-correlated by Spearman's $\rho\left(r_{s}\right)>0.7$ (Kolowski \& Holekamp, 2006). There was a strong positive correlation between farm size and total stock holdings $\left(r_{s}=0.74, \mathrm{P}<0.001\right)$ and therefore farm size was excluded. The full model included the composite attitude score as the response variable, with respondents' estimated total stock holdings, estimated proportion of stock predated, age, culture, and land use as predictor variables. Some respondents omitted one or more of the attitude statements and therefore maximum composite score was modelled as an offset variable.

Our set of candidate models contained all additive combinations of predictors as well as all two-way 

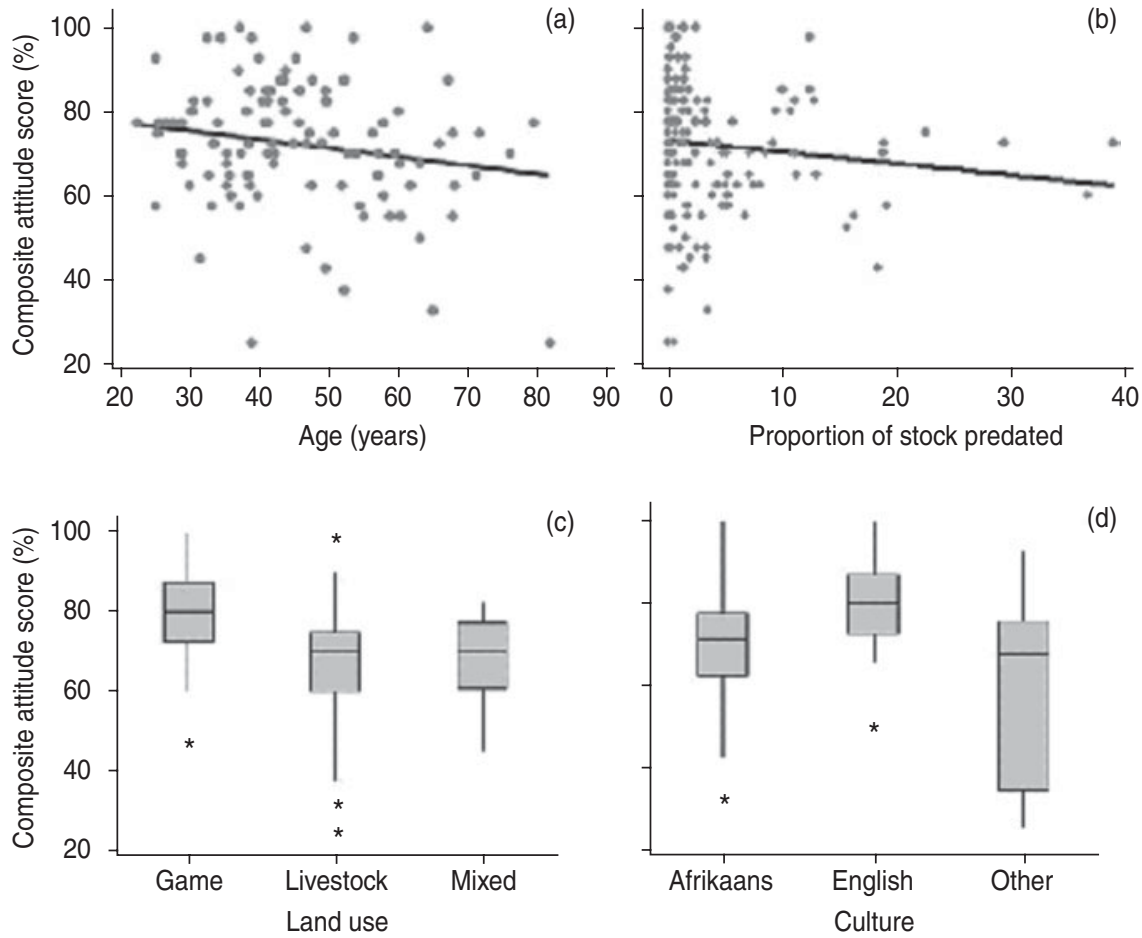

(c)

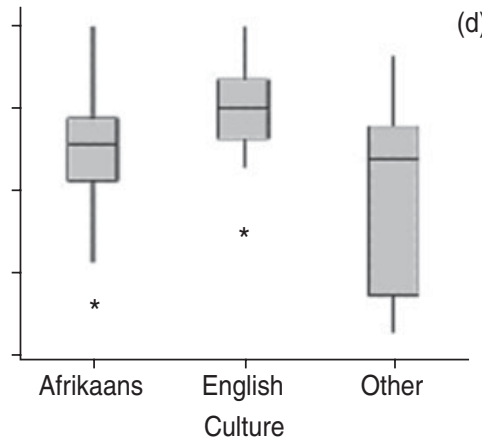

(d)

FIG. 2 Composite attitude scores $(\mathrm{n}=170)$ in relation to characteristics of respondents and their land. Box plots display median, $25 \%$ and $75 \%$ quartiles, maximum, minimum and outliers $\left(^{*}\right)$. Scatter plots show the linear trend line. High scores indicate a positive attitude towards carnivores. interactions. Missing observations were excluded case-wise. We ranked candidate models in order of parsimony, using Akaike's Information Criterion adjusted for small sample size $\left(\mathrm{AIC}_{\mathrm{c}}\right.$; Burnham \& Anderson, 2002). Models within $7 \Delta \mathrm{AIC}_{\mathrm{c}}$ units of the model with the lowest $\mathrm{AIC}_{\mathrm{c}}$ were considered to have sufficient relative support to be included in the final set of explanatory models (Burnham \& Anderson, 2002; Burnham et al., 2011). We excluded any model that was simply a more complicated version (i.e. containing additional parameters) of a nested model with lower $\mathrm{AIC}_{\mathrm{c}}$, to reduce selection of overly complex models (Burnham \& Anderson, 2002). We then used Akaike model weight to determine the relative probability of each model being the most parsimonious in the candidate model set, and summed weights to evaluate the relative importance of determinants (Burnham \& Anderson, 2002). We predicted effect sizes from regression coefficients $(\beta)$. Analysis was conducted using SPSS v. 17 (SPSS, Chicago, USA). Financial values are given in South African rand $\left(\mathrm{ZAR}_{1}=\mathrm{GBP}_{0.08}=\mathrm{USD}_{0.13}\right)_{\text {. }}$

\section{Results}

We interviewed 78 people in the North West Province and 92 in the Waterberg area. With a refusal rate of $4 \%$, nonresponse bias was assumed to be negligible. All but five respondents were white, reflecting typical land-tenure patterns on South African commercial farms (Tladi et al., 2002). As in Marker et al. (2003) we considered commercial farmers to be a homogeneous group and therefore assumed our respondents to be approximately representative of the wider population of commercial farmers in the study area. Although not inherently unrealistic, this assumption could not be verified because there were no reference statistics available for land ownership by ethnic group in the study area.

Most respondents (75\%) were Afrikaans-speaking, 19\% were English-speaking and 6\% were from other cultural groups (3\% German-speaking and 3\% Bantu languagespeaking). Median age was 44 years $\left(Q_{1}=36, Q_{3}=54\right.$, range 23-82).

The total area of the farms surveyed was $5,454 \mathrm{~km}^{2}$ (median $=13.1 \mathrm{~km}^{2}$, range $0.06-960 \mathrm{~km}^{2}$ ), which represents $7.5 \%$ of farmland within the study area. The sample contained an equal proportion of game and livestock farmers (37\% each) and the remaining $26 \%$ were mixed farmers. Total stock holdings were estimated at 183,049 animals (median $=478, \mathrm{Q}_{1}=200, \mathrm{Q}_{3}=900$ ). The estimated total number of animals predated in the year prior to the interview was 2,268 (median $\left.=5, Q_{1}=0, Q_{3}=30\right)$. The estimated median proportion of stock holdings predated by carnivores was $1 \%\left(\mathrm{Q}_{1}=0, \mathrm{Q}_{3}=4 \%\right)$.

Agreement rates (the proportion of respondents who agreed or strongly agreed) for the 10 attitude statements are summarized in Table 1. Attitude statements four and seven were excluded from the composite score, giving Cronbach's $\alpha=0.8$, indicating good internal consistency. In keeping with our predictions, game farmers had more positive attitudes (higher median composite attitude scores) than mixed or livestock farmers (Fig. 2). English-speaking farmers had more positive attitudes than Afrikaansspeaking farmers and other cultural groups (Fig. 2). Age 
TABLE 2 Generalized linear models that were within $7 \mathrm{AIC}_{\mathrm{c}}$ units of the model with the lowest $\mathrm{AIC}_{\mathrm{c}}$, with associated degrees of freedom (df), number of parameters $(\mathrm{k}), \mathrm{AIC}_{\mathrm{c}}, \Delta \mathrm{AIC}_{\mathrm{c}}$ and Akaike model weight.

\begin{tabular}{lllcrr}
\hline Model & df & $k$ & AICc & DAICc & Weight \\
\hline Cultural group $\times$ land use & 8 & 9 & 995.31 & 0 & 0.9192 \\
Age + proportion of stock lost + land use & 4 & 5 & $1,001.519$ & 6.21 & 0.0412 \\
Cultural group + land use & 4 & 5 & $1,001.694$ & 6.38 & 0.0378 \\
\hline
\end{tabular}

TABLE 3 Estimated regression coefficients $(\hat{\beta})$ and their exponential values $\hat{\beta}$, from generalized linear models that were within 7 AIC $\mathrm{C}_{\mathrm{c}}$ units of the model with the lowest $\mathrm{AIC}_{\mathrm{c}}$. Values in bold differ significantly from zero.

\begin{tabular}{|c|c|c|c|}
\hline Model $^{*}$ & $\hat{\beta}$ & $\pm \mathrm{SE}(\hat{\beta})$ & $\operatorname{Exp}(\hat{\beta})$ \\
\hline Cultural group $=$ Afrikaans-speaking $\times$ land use $=$ game & 0.062 & 0.0409 & 1.064 \\
\hline Cultural group $=$ Afrikaans-speaking $\times$ land use $=$ livestock & -0.079 & 0.0426 & 0.924 \\
\hline Cultural group $=$ Afrikaans-speaking $\times$ land use $=$ mixed & -0.088 & 0.0421 & 0.916 \\
\hline Cultural group $=$ English-speaking $\times$ land use $=$ game & 0.134 & 0.0441 & 1.143 \\
\hline Cultural group $=$ English-speaking $\times$ land use $=$ livestock & 0.043 & 0.0646 & 1.044 \\
\hline Cultural group $=$ English-speaking $\times$ land use $=$ mixed & 0.022 & 0.0485 & 1.023 \\
\hline Cultural group $=$ other $\times$ land use $=$ game & 0.087 & 0.1154 & 1.091 \\
\hline Cultural group $=$ other $\times$ land use $=$ livestock & -0.534 & 0.1943 & 0.586 \\
\hline
\end{tabular}

${ }^{*}$ Reference category: cultural group $=$ other $\times$ land use $=$ mixed purpose

and stock losses were negatively related to composite attitude scores, whereas total stock holdings were positively related to attitudes (Fig. 2). The same is true of farm size, which was strongly positively correlated with stock holdings. Respondents who killed carnivores (58\%) had significantly lower median composite attitude scores than those who did not $(U=2,730.5, Z=-3.658, \mathrm{P}<0.001, \mathrm{n}=170)$, indicating a clear link between attitude and persecutory behaviour.

The global additive model showed no evidence of a lack of fit $\left(\chi_{156}^{2}=132.12, \hat{c}=0.85, \mathrm{n}=164\right)$. Three of 42 candidate models were within 7 Akaike units of the top-ranked model (Table 2). Land use (summed Akaike weight 99.9) and culture (summed Akaike weight 95.8) were by far the most influential variables. Age (summed Akaike weight 4.3), proportion of stock predated (summed Akaike weight 4.2) and total stock holdings (summed Akaike weight o.1) had comparatively little effect. The top-ranked model was an interaction between land use and culture (Table 3), indicating that the effect of those predictors differed among their sub-categories. Regression coefficients were taken from the top-ranked model, which received considerably greater support than any other model (0.92 Akaike weight). The coefficients indicate that, after controlling for the effect of other variables, predicted composite attitude scores among English-speaking game farmers were $14 \%$ higher than expected scores among the reference category (cultural group $=$ other, land use $=$ mixed). Predicted scores for Afrikaans-speaking mixed farmers and livestock farmers in the cultural group 'other' were $8 \%$ and $41 \%$ lower, respectively, than the reference category.

\section{Discussion}

Quantifying the attitudes of landowners towards carnivores and understanding the factors that determine them is instrumental to conservation planning and increasing tolerance of carnivores (Naughton-Treves et al., 2003; Zimmermann et al., 2005; Romanach et al., 2007; Anthony et al., 2010). Although negative attitudes and the intention to kill carnivores are not always correlated with actual carnivore removals (Romanach et al., 2007), strong positive correlation in our study area indicates that influencing attitudes to carnivores can reasonably be expected to produce concomitant alterations in persecutory behaviour.

Attitudes are functions of affective (emotional) and cognitive components (Vlek \& Steg, 2007; Heberlein, 2012). Changing attitudes therefore involves communicating relevant and credible messages whose emotional and rational content appeals to target recipients (Vlek \& Steg, 2007), and responses to the individual attitude statements provide a good starting point for the development of such material. Many respondents felt that carnivores were overabundant (35\%) and inflicted financial losses (62\%) and that lethal control of suspected predators was the most costeffective method of limiting predation losses (31\%). These beliefs constitute compelling motives for killing carnivores but there is a lack of empirical data with which to address them. Robust, contemporary estimates of carnivore population size and distribution are lacking for most South African carnivore species (Friedmann \& Daly, 2004), as is information on carnivore ecology outside protected areas. 
Likewise, there have been few studies of human-carnivore conflict in South Africa (Thorn et al., 2012).

Recommended themes for future research therefore include the effect of predators on farming profitability, carnivore diet and predation rates on farmland, carnivore population status, the efficacy and cost of non-lethal antipredation measures, and the effect of persecution on carnivore populations. Such studies would provide information about the effects of carnivores on people and the implications of different management and conservation options. Species-specific information would be useful, given that attitudes and behaviour towards carnivores often vary according to species (Romanach et al., 2007). Local and regional measurements would help to place the data in an appropriately broad context. Communicating research findings to farming communities that can benefit from them should also be an integral element of future studies.

In the meantime it may be helpful to highlight the utilitarian benefits of carnivores (Davenport et al., 2010) in terms of the financial value of sustainable hunting (Marker et al., 2003; but see Treves, 2009) and carnivore-based ecotourism (Marker et al., 2003; Lindsey et al., 2005a), pest and intra-guild population control (Prugh et al., 2009) and improving the health of prey populations by removing weak or diseased animals (Davenport et al., 2010). It may also be possible to influence the customers of hunting, tourism and animal production businesses and increase demand for ecologically sustainable products as consumers are often willing to pay more for products that are perceived as ecologically responsible (Brécard et al., 2009). Our modelling results (Tables $2 \& 3$ ) elucidate characteristics that can be used to determine target recipients for conflictmitigation activities. The results indicate that in northern South Africa the attitudes of commercial farmers towards carnivores are influenced by cultural and land-use attributes more than by economic factors such as stock holdings or rates of loss. Thus, activities aimed at improving attitudes should focus on areas where livestock, and particularly mixed-purpose, farming is prevalent. Demographically, areas with high proportions of Afrikaans-speaking farmers are also a priority. Interventions aimed at fortifying positive attitudes should focus on game-farming areas, especially those with large English-speaking populations. Cultural influences on attitudes can be difficult to address because culture incorporates social and psychological factors that are central to self-perception (Vlek \& Steg, 2007). Nevertheless, it is possible to influence deeply ingrained attitudes if the source of communication is perceived as fair, legitimate and trustworthy (Anthony et al., 2010) and if the information appropriately incorporates the norms, values and beliefs of the target cultural group (Vlek \& Steg, 2007).

Game farming is increasingly common in South Africa (Bothma, 2005) and therefore it is promising that game farmers hold more positive attitudes to carnivores. It is somewhat surprising, however, because few of the antipredation measures available for livestock farmers (e.g. herding, guarding animals, kraaling, deterrent devices) are feasible for extensively managed game (Shivik, 2006). It may be that game farmers are less aware of (cognitive component) and so less distressed by (affective component) predation losses because their stock is dispersed over a larger area and is counted less frequently than intensively managed stock. The socio-economic status of game-farm owners may also differ from other farming groups. For example, game farming is considered to require lower input of capital and offer greater profitability than cattle or smallstock farming (Absa, 2003), and therefore game farmers may be comparatively affluent and less adversely affected by predation losses. Further investigation of such factors may produce useful insights into the attitude gap between farmers with different land uses.

Nevertheless, reducing the frequency of persecutory behaviour may require more than just a change in attitudes to carnivores. Experience is also an important driver of behaviour (Heberlein, 2012) and therefore communicating persuasive educational information may not necessarily change behaviour if farmers have negative experiences of carnivores (Heberlein, 2012). It may be necessary to engage in outreach and extension activities that accurately quantify and/or reduce predation to acceptable levels, encourage good husbandry practices and provide carnivore-based economic benefits (e.g. carnivore-based tourism). Marker et al. (2003) reported positive results from extension activities among Namibian farming communities that are culturally similar to those in our study area. Greater awareness of conservation issues and the ability to accurately diagnose the cause of stock losses meant that persecution of cheetahs was reduced and was more closely linked with actual rather than perceived predation problems.

Human-wildlife conflicts are a product of complex interactions between ecological, socio-economic and political systems (Graham et al., 2005; Anthony et al., 2010; Davenport et al., 2010). Unravelling this complexity and reducing conflict requires adaptive, interdisciplinary approaches that facilitate informed dialogue between key stakeholders (Davenport et al., 2010; St John et al., 2010), including the rural communities who typically experience adverse effects of wildlife. Engaging these people in management planning and conflict resolution is particularly important in South Africa because the institutions responsible for managing human-wildlife conflict and enforcing biodiversity legislation are hampered by a lack of financial and human resource capacity (Anthony et al., 2010). Comprehensive changes in persecutory behaviour cannot be compelled and sustainable conflict-mitigation strategies often rely on persuasion rather than enforcement. 
Our findings therefore provide insight into previously under-studied human dimensions of conflict between people and carnivores on South African farmland and a starting point for designing acceptable and practical conflict-mitigation activities. Such activities may also influence wider regional metapopulation function as a result of spatial and genetic linkages between carnivore populations in the study area and populations in adjacent countries (Lindsey et al., 2004, 2009; Thorn et al., 2012).

\section{Acknowledgements}

We are grateful to the interview respondents and to Lapalala Wilderness and Welgevonden Private Game Reserve for logistical assistance. We thank S. Uzzell and the Earthwatch Institute for their support, and two anonymous reviewers for helpful comments. We also thank Land Rover Centurion for sponsoring the project, and the Endangered Wildlife Trust, Knowsley Safari Park, the Rufford Small Grants Foundation, the University of Brighton, and the Leverhulme Trust for providing funding.

\section{References}

A bSA (2003) Game Ranch Profitability in Southern Africa, 3rd edition. Absa, Johannesburg, South Africa.

Anthony, B.P., Scott, P. \& Anty pas, A. (2010) Sitting on the fence? Policies and practices in managing human-wildlife conflict in Limpopo Province, South Africa. Conservation and Society, 8, 225-240.

Baillie, J.E.M., Griffiths, J., Turvey, S.T., Loh, J. \& Collen, B. (2010) Evolution Lost: Status and Trends of the World's Vertebrates. Zoological Society of London, London, UK.

Bотнма, J.d.P. (2005) Extensive Wildlife Production in South Africa. Keynote address: Wildlife Seminar, Northern Game Farmers' Organization, Pretoria, South Africa, 11 March 2005.

Brécard, D., Hlaimi, D., Lucas, S., Perraudeau, Y. \& Salladarré, F. (2009) Determinants of demand for green products: an application to eco-label demand for fish in Europe. Ecological Economics, 69, 115-125.

Burnham, K.P. \& Anderson, D.R. (2002) Model Selection and Multimodel Inference: A Practical Information-Theoretic Approach. Springer-Verlag, New York, USA.

Burnham, K.P., Anderson, D.R. \& Huyvaert, K.P. (2011) AIC model selection and multimodel inference in behavioral ecology: some background, observations, and comparisons. Behavioral Ecology and Sociobiology, 65, 23-35.

Cortina, J.M. (1993) What is coefficient alpha? An examination of theory and applications. Journal of Applied Psychology, 78, 98-104.

Davenport, M.A., Nielsen, C.K. \& Mangun, J.C. (2010) Attitudes toward mountain lion management in the midwest: implications for a potentially recolonizing large predator. Human Dimensions of Wildlife: An International Journal, 15, 373-388.

DE KLERK, A. (2003) The Waterberg Biosphere Reserve: a land-use model for ecotourism development. MSc thesis. University of Pretoria, Pretoria, South Africa.
Department of Agriculture, Forestry and Fisheries (2010) Abstract of Agricultural Statistics. Department of Agriculture, Forestry and Fisheries, Pretoria, South Africa.

Friedmann, Y. \& Daly, D. (eds) (2004) Red Data Book of the Mammals of South Africa: A Conservation Assessment. CBSG Southern Africa, Conservation Breeding Specialist Group (SSC/IUCN) \& The Endangered Wildlife Trust, Johannesburg, South Africa.

Graham, K., Beckerman, A.P. \& Thirgood, S. (2005) Human-predator-prey conflicts: ecological correlates, prey losses and patterns of management. Biological Conservation, 122, 159-171.

Heberlein, T.A. (2012) Navigating environmental attitudes. Conservation Biology, 26, 583-585.

Inskip, C. \& ZimmermanN, A. (2009) Human-felid conflict: a review of patterns and priorities worldwide. Oryx, 43, 18-34.

IUCN (2012) Table 4a: Red List category summary for all animal classes and orders. Http://www.iucnredlist.org/documents/ summarystatistics/2011_2_RL_Stats_Table4a.pdf [accessed 6 November 2013].

Kolowski, J.M. \& Holekamp, K.E. (2006) Spatial, temporal, and physical characteristics of livestock depredations by large carnivores along a Kenyan reserve border. Biological Conservation, 128, 529-541.

Lindsey, P., DU Toit, J.T. \& Mills, M.G.L. (2004) The distribution and population status of African wild dogs (Lycaon pictus) outside protected areas in South Africa. South African Journal of Wildlife Research, 34, 143-151.

Lindsey, P., Marnewick, K., Davies-Mostert, H., Rehse, T., Mills, M.G.L., Brummer, R. et al. (eds) (2009) Cheetah (Acinonyx jubatus) Population Habitat Viability Assessment Workshop Report. Conservation Breeding Specialist Group (SCC/IUCN)/CSBG Southern Africa \& The Endangered Wildlife Trust, Johannesburg, South Africa.

Lindsey, P.A., Alexander, R.R., du Toit, J.T. \& Mills, M.G.L. (2005a) The potential contribution of ecotourism to African wild dog Lycaon pictus conservation in South Africa. Biological Conservation, 123, 339-348.

Lindsey, P.A., DU Toit, J.T. \& Mills, M.G.L. (2005b) Attitudes of ranchers towards African wild dogs Lycaon pictus: conservation implications on private land. Biological Conservation, 125, 113-121.

Mackinnon, J. \& Mackinnon, K. (1986) Review of the Protected Areas System in the Afrotropical Realm. IUCN, Gland, Switzerland.

Marker, L.L., Mills, M.G.L. \& Macdonald, D.W. (2003) Factors influencing perceptions of conflict and tolerance towards cheetahs on Namibian farmlands. Conservation Biology, 17, 1290-1298.

Naughton-Treves, L., Grossberg, R. \& Treves, A. (2003) Paying for tolerance: rural citizens' attitudes toward wolf depredation and compensation. Conservation Biology, 17, 1500-1511.

Ogada, M.O., Woodroffe, R., Oguge, N.O. \& Frank, L.G. (2003) Limiting depredation by African carnivores: the role of livestock husbandry. Conservation Biology, 17, 1521-1530.

Pimm, S.L., Russell, J., Gittleman, J.L. \& Brooks, T.M. (1995) The future of biodiversity. Science, 269, 347-350.

Prugh, L.R., Stoner, C.J., Epps, C.W., Bean, W.T., Ripple, W.J., Laliberte, A.S. \& Brashares, J.S. (2009) The rise of the mesopredator. BioScience, 59, 779-791.

Romanach, S.S., Lindsey, P.A. \& Woodroffe, R. (2007) Determinants of attitudes towards predators in central Kenya and suggestions for increasing tolerance in livestock-dominated landscapes. Oryx, 41, 185-195.

SHIVIK, J.A. (2006) Tools for the edge: what's new for conserving carnivores. BioScience, 56, 253-259.

St John, F.A.V., Edwards-Jones, G. \& Jones, J.P.G. (2010) Conservation and human behaviour: lessons from social psychology. Wildlife Research, 37, 658-667. 
Thorn, M., Green, M., Dalerum, F., Bateman, P.W. \& Scott, D. (2012) What drives human-carnivore conflict in the North West Province of South Africa? Biological Conservation, 150, 23-32.

Tladi, B., Baloyi, T. \& Marfo, C. (2002) Settlement and land-use patterns. In North West Province State of the Environment Report (eds D. Walmsley, J. Walmsley, S. Mangold \& M. Kalule-Sabiti). Directorate of Environment and Conservation Management. North West Department of Agriculture, Conservation and Environment, Mmabatho, South Africa.

Treves, A. (2009) Hunting for large carnivore conservation. Journal of Applied Ecology, 46, 1350-1356.

VleK, C. \& STEG, L. (2007) Human behaviour and environmental sustainability: problems, driving forces, and research topics. Journal of Social Issues, 63, 1-19.

White, P.C.L. \& WARD, A.L. (2010) Interdisciplinary approaches for the management of existing and emerging human-wildlife conflicts. Wildlife Research, 37, 623-629.
Woodroffe, R. \& GinsberG, J.R. (2000) Ranging behaviour and vulnerability to extinction in carnivores. In Behaviour and Conservation (eds L.M. Gosling \& W.J. Sutherland), pp. 125-140. Cambridge University Press, Cambridge, UK.

Zimmermann, A., Walpole, M.J. \& Leader-Williams, N. (2005) Cattle ranchers' attitudes to conflicts with jaguar Panthera onca in the Pantanal of Brazil. Oryx, 39, 406-412.

\section{Biographical sketches}

Michelle Thorn and Matt Green's interests include mammal distribution, practical field protocols for conservation monitoring and the management of human-animal conflicts. KeLLy MARNEWICK is the manager of the Endangered Wildlife Trust's Carnivore Conservation Programme. She is particularly interested in cheetahs outside protected areas and in human-wildlife conflict. DAWN S сотT's research focuses on mammalian conservation biology and landscape ecology and she is the principal investigator of the Brown Hyaena Research Project in South Africa. 